\title{
Molecular identification of five species of family Chaetomiaceae (Sordariomycetes, Ascomycota) from Iraqi soil
}

\author{
MUSTAFA A. AL-DOSSARY ${ }^{1, \boldsymbol{v}}$, SHAYMAA S. RAHEEM ${ }^{1}$, MAYSOON K. ALMYAH ${ }^{2}$ \\ ${ }^{1}$ Department of Ecology, College of Science, University of Basrah. Basrah, Iraq. `email: mustafa.najem@uobasrah.edu.iq \\ ${ }^{2}$ General Directorate of Education in Basrah. Basrah, Iraq
}

Manuscript received: 13 January 2020. Revision accepted: 13 February 2021.

\begin{abstract}
Al-Dossary MA, Raheem SS, Almyah MK. 2021. Molecular identification of five species of family Chaetomiaceae (Sordariomycetes, Ascomycota) from Iraqi soil. Biodiversitas 22: 1277-1284. Five ascomycetes fungi within the family Chaetomiaceae (Sordariomycetes, Ascomycota) were isolated from Iraqi agricultural soil and identified by phenotypic characteristics and molecular analysis. Chaetomium ascotrichoides and C. subaffine are reported for the first time from the Iraqi mycobiota. Amesia atrobrunnea, Collariella bostrychodes and Ovatospora brasiliensis were previously reported from Iraq as Chaetomium atrobrunneum, C. bostrychodes, and $C$. brasiliense respectively. All reported species were provided with brief characterizations and photographs
\end{abstract}

Keywords: Agriculture soils, Ascomycetes, Chaetomiaceae, Iraq

\section{INTRODUCTION}

Chaetomiaceae (Sordariomycetes) is one of the largest families of saprotrophic ascomycete fungi with more than 300 species. The type species of this family is Chaetomium globosum Kunze. The species within this family are capable of colonizing various substrates and are wellknown for their ability to degrade cellulose and to produce a variety of bioactive metabolites. They are present in different microhabitats, including soil, air, decomposed cotton, paper, moist walls, damaged buildings. In the plant rhizoplane, Chaetomiaceae are almost strictly saprophytic and have been shown to be antagonistic against several plant pathogens (Adhikari et al. 2017; Zhang et al.2017; Ruppavalli et al. 2019). Chaetomium is well known for its properties for agriculture application. It has a broad spectrum antagonistic ability against wide range of plant pathogens due to production of diverse metabolites (antibiosis) such as chaetomin, cochliodinol, and chaetosin (Moya et al. 2016).

Chaetomium spp. used as fungicide, the fungus has been formulated into bio-pellets and bio powders under the name Ketomium for the biological control of plant diseases such as tomato wilt and basal rot of corn, also used as bioinsecticide for the biological control of sucking insect pests (Soytong et al. 2001; Alsalhi et al. 2018).

Usually, ostiolate ascomata with hairs around the ostiole are one of the common features of this family, also evanescent asci with different shapes that range from clavate to fasciculate with brown to gray-brown ascospores which usually possessing one or two germ pores (von Arex et al.1986). Later, von Arx et al. (1986) established new taxonomic characters for this family, species with ovate or obovate to globose ascomata with textura intricata walls were included. These species exhibit diverse hair morphology that ranges from erect to coiled. Several anamorphic genera have been associated with the genus Chaetomium, such as Acremonium-like anamorph (Wang et al. 2016a).

At present, the species within this family possesses largely defined morphological variety, many genera in the family have been reevaluated and redefined, and many new genera have been proposed recently. These changes result in a lot of new combinations (Wang et al. 2016a). For this reason, it is necessary to re-understand the diversity of Chaetomiaceae in Iraqi.

The molecular identification of this fungal genus is highly limited, and additional molecular studies on this genus are necessary (Wang et al. 2014). Thus, great effort has been made to classify, identify, and accurately grouping different species of Chaetomium, based on DNA sequencing (Sekhar et al. 2018). Due to the lack of genetic studies on the species belonging to this genus in Iraq, this work aimed to investigate the fungal diversity within the family Chaetomiaceae by using morphological characters and molecular sequencing.

\section{MATERIALS AND METHODS}

\section{Sample collection}

Sixteen soil samples were collected from four different agricultural areas at a depth of $5-10 \mathrm{~cm}$ in Basrah Province, Iraq, i.e. Abu-Alkasib, Aljazera, Alkarmah, and Almdinah (Figure1). Approximately 150-200 g was collected from each soil sample. Soil samples were put in clean bags, then transferred to the laboratory, and maintained at $4{ }^{\circ} \mathrm{C}$ until further use. 


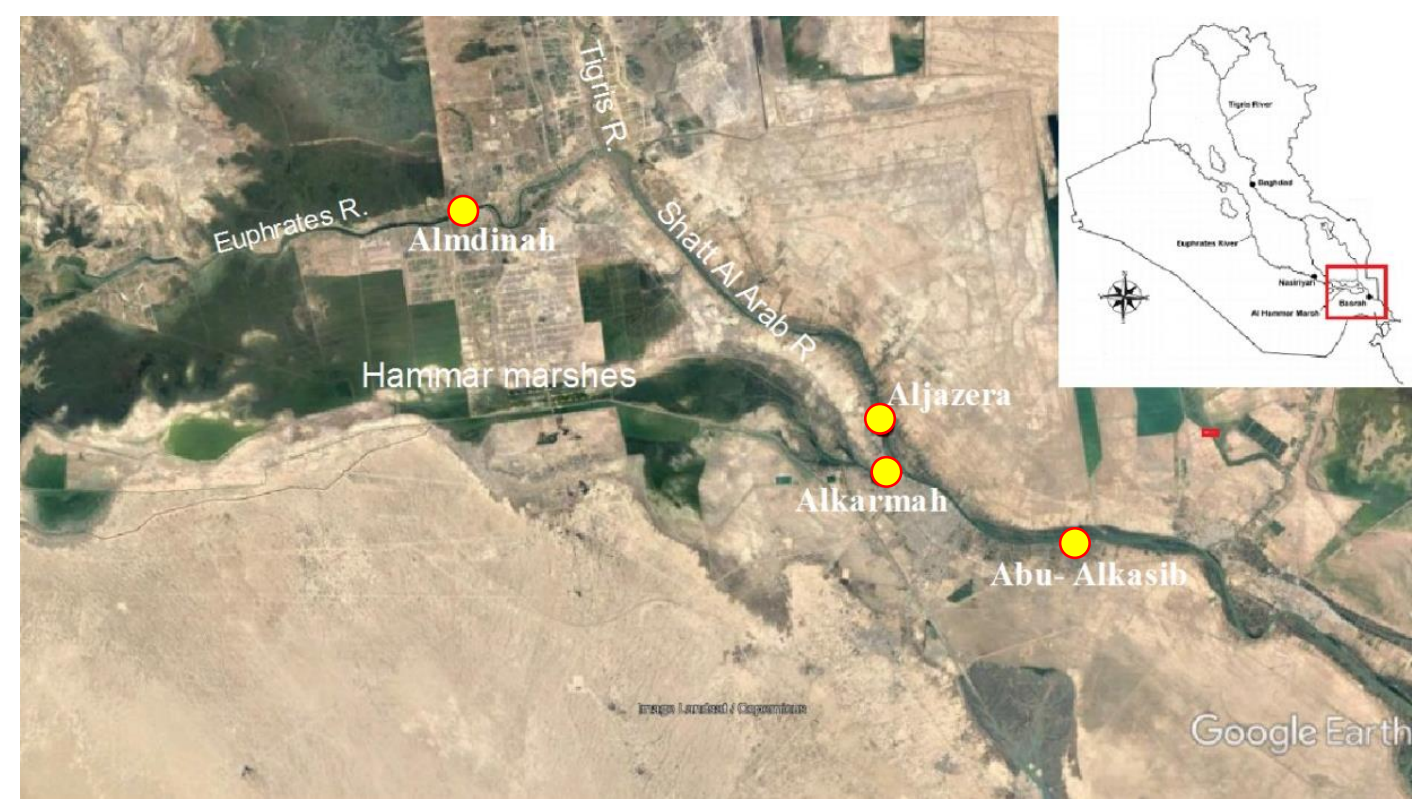

Figure 1. Study area in Basrah Province, Iraq

\section{Isolation of fungi}

The plate dilution method (Davet, 2000) was used to isolate the ascomycetous fungi within the family Chaetomiaceae. From each soil sample, a total of $10 \mathrm{~g}$ was suspended in $100 \mathrm{~mL}$ of sterile distilled water and diluted up to $\times 10^{3}$ after thorough shaking for $10 \mathrm{~min}$. From each dilution, approximately $1 \mathrm{~mL}$ was transported to a sterile Petri dish. Then, approximately $15 \mathrm{~mL}$ of sterile medium was added. For primary isolation, potato dextrose agar (PDA) and oatmeal agar (OA) media (Hi media, India) supplemented with the antibiotic chloramphenicol (250 $\mathrm{mg} / \mathrm{L}$ ) were used. All the dishes were incubated at $25{ }^{\circ} \mathrm{C}$ for 7-14 days. All distinct colonies were subjected to additional purification by subculturing on plates containing OA media.

\section{Phenotypic identification}

The diameters of each purified 7-14-day-old colony on OA media were measured. Front and reverse colony colors and sporulation grades were also observed. Then, glass slides were prepared from each purified culture and examined under a compound microscope (Samson et al. 2010). Appropriate keys were used for the phenotypic identification of the isolated fungi (Guarro et al. 2012; Wang et al. 2016 a,b).

\section{DNA extraction and phylogenetic identification}

Pure cultures of fungi at 7-14-days old were used for DNA extraction. The technique designated by Mirhendi et al. (2006) was used for DNA extraction and PCR amplification. PCR amplification and sequencing were performed by using NL1 and NL4 primers for the large subunit of ribosomal DNA (LSU) with the forward primer NL1 (5'-GCA TAT CAA TAA GCG GAG GAA AAG-3') and reverse primer NL4 (5'-GGT CCG TGT TTC AAG ACGG-3') (Friggens et al. 2017). All subsequent operations were performed in accordance with (Mirhendi et al. 2006). The purification and sequencing of the PCR products were done at Macrogen, South Korea. The identification of fungal isolates was done by using BLAST (Altschul et al. 1997) in GenBank (Sayers et al. 2021). The construction of the neighbor-joining phylogentic tree was based on the D1/D2 region of the large subunit rRNA gene and performed in MAFFT (Mirhendi et al. 2006). Bootstrap values were calculated with 500 replicates.

\section{RESULTS AND DISCUSSION}

\section{Isolates}

On the basis of phenotypic characteristics, 20 isolates were identified as members of the family Chaetomiaceae. Isolates that represented different species were included, whereas identical strains were excluded (Table 1).

Chaetomium species are usually identified according to phenotypic characteristics with emphasis on special features, such as superficial and usually ostiolate ascomata that are surrounded by hairs (Aggarwal et al. 2008), or the presence of stalked, thin-walled, evanescent, eight- spores asci (von Arx et al. 1986).

High morphological diversity has been found for these common features, thus relying on morphological characters alone is insufficient for the identification of this genus (Abdel-Azeem, 2020). Therefore, the accurate identification of the species belonging to this genus should not be based on phenotypic features only; molecular techniques should be also used (Quyet et al. 2018).

When we subjected all isolates of Chaetomium to PCR amplification by using primers NL1and NL4, the number of isolates decreased to only 9 species belonging to five genera, among them (Amesia, Collariella, and Ovatospora) were recorded for the first time in Iraq. These genera were 
recorded for the first time in Iraq. The NL1and NLA primers are widely used in rDNA sequencing either alone or with other primers for thorough and accurate phylogenetic investigation of different fungal genera (Zhang et al.2017; Sekhar et al. 2018 ). The molecular identification of Chaetomium species by using the LSU sequence was conducted through GenBank BLAST. The identification percentage was $99-100 \%$.

\section{Taxonomy}

Nine species belonging to the family Chaetomiaceae were recognized through phylogenetic inference and phenotypic characters. Of these species, five belong to the genus Chaetomium, and the others belong to other four genera within the Chaetomiaceae family, namely, Amesia atrobrunnea, Collariella bostrychodes, Ovatospora brasiliensis, and Trichocladium seminis-citrulli. The use of LSU analysis facilitated the identification of the isolates as clearly reflected by the phylogenetic tree of the species (Figure 2). Several previously reported studies were in agreement with our study Wang et al. (2016a,b). Five of these 9 species were recorded for the first time in Iraq and are described here.

Table 1. Comparison between phenotypic and phylogenetic identification for the fungal isolates

\begin{tabular}{lll}
\hline \multirow{2}{*}{ No. of isolates } & \multicolumn{1}{c}{ Fungal species } \\
\cline { 2 - 3 } & \multicolumn{1}{c}{ Phenotypic identification } & \multicolumn{1}{c}{ Phylogenetic identification } \\
\hline 2 & Chaetomium atrobrunneum & Amesia atrobrunnea (Ames) Wang \& Samson \\
1 & C. ascotrichoides & Chaetomium ascotrichoides Calviello \\
3 & C. elatum & C. elatum Kunze \\
3 & C. globosum & C. globosum Kunze \& Schmidt \\
3 & C. ascotrichoides & C. madrasense Natarajan \\
2 & C. seminis citrulli & Trichocladium seminis-citrulli (Sergeeva) X.Wei Wang \& Houbraken \\
2 & C. globosum & C. subaffine Sergeeva \\
3 & C. bostrychodes & Collariella bostrychodes (Zopf) X. Wei Wang \& Samson \\
1 & C. brasiliense & Ovatospora brasiliensis (Batista \& Pontual) Wang \& Samson \\
\hline
\end{tabular}

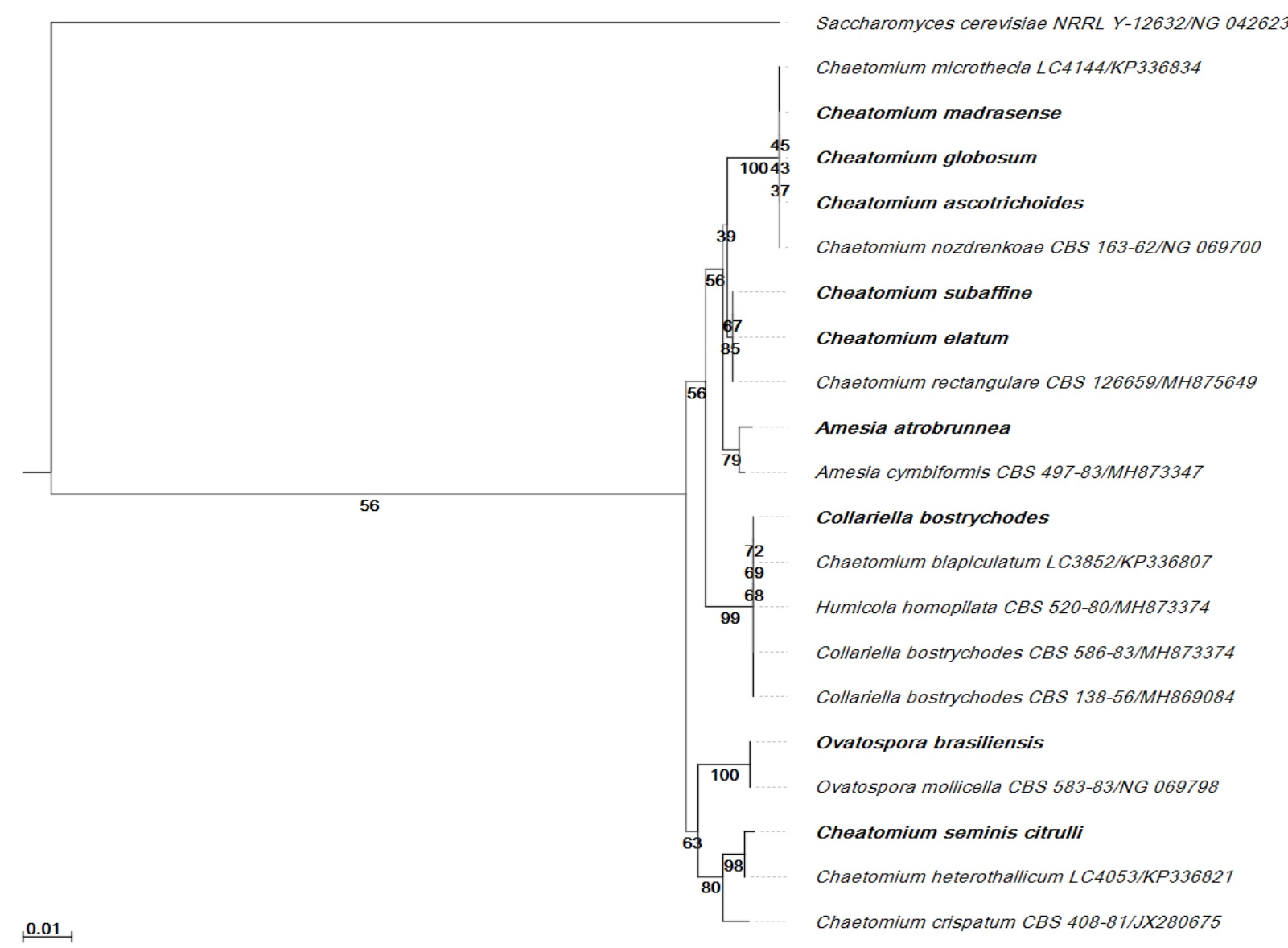

Figure 2. Phylogenetic tree of the family Chaetomiaceae with closely related taxa from GenBank and their accession numbers, derived from neighbor-joining analysis of 28s rDNA D1/D2 domain sequences. Frequencies with which a given branch appeared in 500 bootstrap replications are represented under branches 


\section{Amesia atrobrunnea}

Amesia atrobrunnea (Ames) Wang \& Samson, Stud. Mycol. 84: 158 (2016a). (Figure 3)

Basionym: Chaetomium atrobrunneum Ames, Mycologia 41: 641. 1949.

This species was characterized by superficial, ostiolate ovate, or subglobose ascomata with dimensions of 75-165 $\mu \mathrm{m} \times 70-140 \mu \mathrm{m}$, black in reflected light. The wall of the ascomata exhibited textura angularis in surface view and was black to dark brown in color. The hairs were flexuous, smooth, and septate and were 2.3-3.5 $\mu \mathrm{m}$ in diameter near the base. This species possessed eight ascospores and clavate, evanescent, 9-22 $\mu \mathrm{m}$-long asci. The ascospores were fusiform or elongate and turned dark brown when they matured7.5-10× $4-5.5 \mu \mathrm{m}$. They possessed an apical germ pore at the more attenuated end. Anamorph stage unknown.

Colony morphology: The colonies exhibited good growth and matured within 7 days on OA medium at 25 ${ }^{\circ} \mathrm{C}$. They were nearly 40-50 $\mathrm{mm}$ in diameter and appeared black due to the presence of ascomata together with ascospores. They lacked aerial mycelium, and they were grayish to black in color in reverse.

Material examined: this fungus was isolated from two soil samples taken from Abu-Alkasib and Almdinah, Basrah Province. GeneBank accession number LC600695.

This species was previously named Cheatomium atrobrunneum, Wang et al. (2016 a) transfer this species to a new genus Amesia based on phylogenetic analysis. This genus shows high variety in ascomatal hair and ascospore morphology and is readily isolated from diverse locations (Wang et al. 2016a). Phylogenetic analysis revealed that this species clustered with $A$. cymbiformis in the same clade (Figure 2).

The result was consistent with Wang et al.( 2016 a) showing that these two species are associated with each other and can be distinguished on the basis of ascospore size and shape. This species can grow at temperatures reaching $47^{\circ} \mathrm{C}$, and numerous isolates of this fungus have been proven to cause systemic infections in humans ( $\mathrm{Li}$ et al. 2012; de Hoog et al. 2013).

\section{Chaetomium ascotrichoides}

Chaetomium ascotrichoides Calviello, Revista Mus. Argent. Cien. Nat. B. Aires, Bot. 3: 372. 1972. (Figure 4)

This species is characterized by superficial, olivaceous, ovate, or obovate ascomata with dimensions of 170-290 $\mu \mathrm{m}$ $\times 130-255 \mu \mathrm{m}$, black in reflected light. The ascomatal wall presented textura epidermoidea, brown in color. Hairs are flexuous, finely verrucose, 2.2-3.6 $\mu \mathrm{m}$ in diameter near the base. Around the ostiole, the hairs become shortened and constricted at the septa. It had eight ascospores within clavate, stalked, evanescent, 17-36 $\mu$ m-long asci. The ascospores were broadly limoniform, occasionally triangleshaped in side view, and became slightly apiculate at both ends. They turn brown when mature. Their dimensions are 9.5-11 $\mu \mathrm{m} \times 8.5-9.5 \mu \mathrm{m} \times 6.5-7.5 \mu \mathrm{m}$. They have an apical germ pore. Anamorph stage unknown.

Colony morphology: The colonies exhibited good growth and matured within 7-10 days on OA medium at 25 ${ }^{\circ} \mathrm{C}$. They were nearly $40-50 \mathrm{~mm}$ in diameter, olivaceous black in color, and possessed white aerial hyphae. They were black in reverse.

Material examined: this fungus was isolated from agricultural soil collected from Abu-Alkasib, Basrah Province. GeneBank accession number LC600694.

Morphologically, this species is comparable with Chaetomium madrasense (von Arx et al. 1986). Our phylogenetic tree clustered these two species together. This result was similar to the result of Wang et al. (2016b). We can distinguish this species from $C$. madrasense due to the shape of ascomatal hairs, which were irregularly branched or flexuous in $C$. ascotrichoides but coiled in $C$. madrasense, and the size of the ascospores, were narrower in this species $(6.5-7 \mu \mathrm{m})$ than in $C$. madrasense $(7.5-8.5$ $\mu \mathrm{m})$.

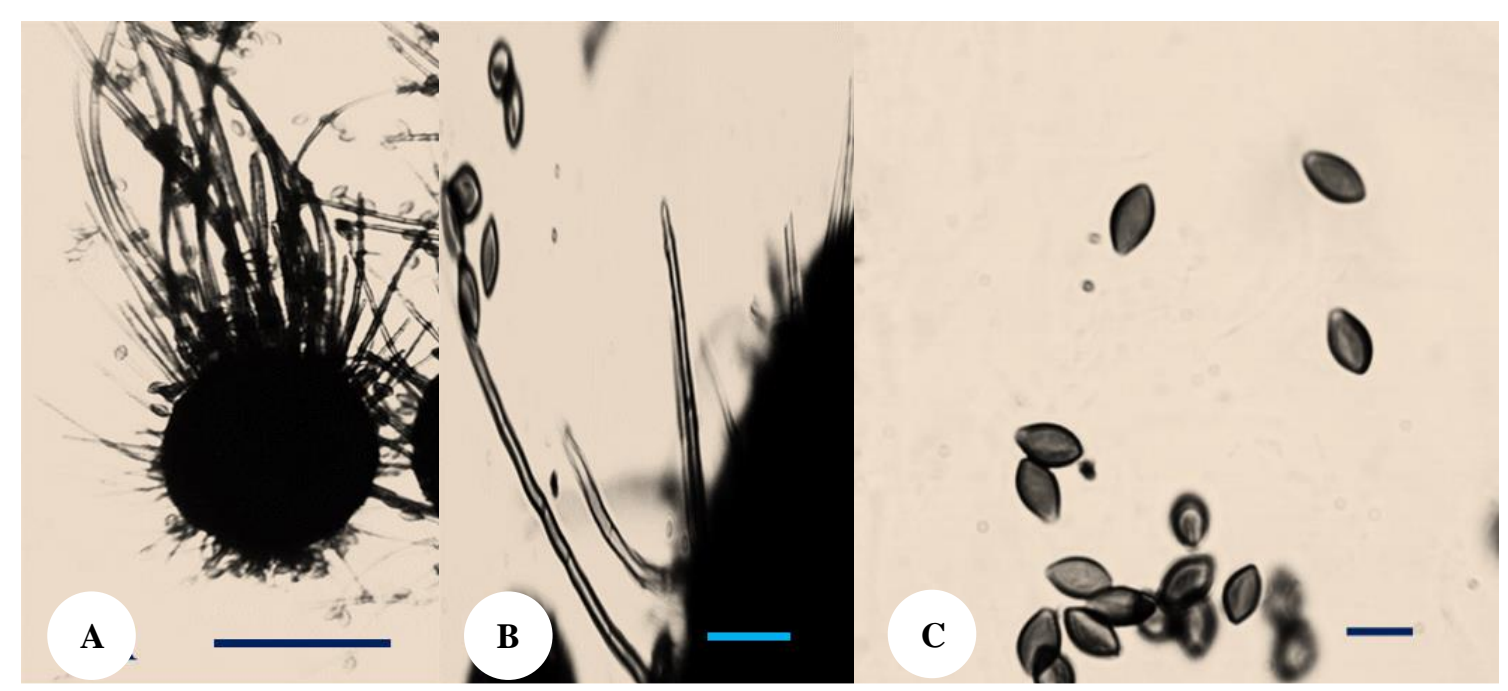

Figure 3. Amesia atrobrunnea. A. Ascoma. B. Ascomatal hairs. C. Ascospores. Bars: A = $107 \mu \mathrm{m} ; \mathrm{B}=16 \mu \mathrm{m} ; \mathrm{C}=10 \mu \mathrm{m}$ 


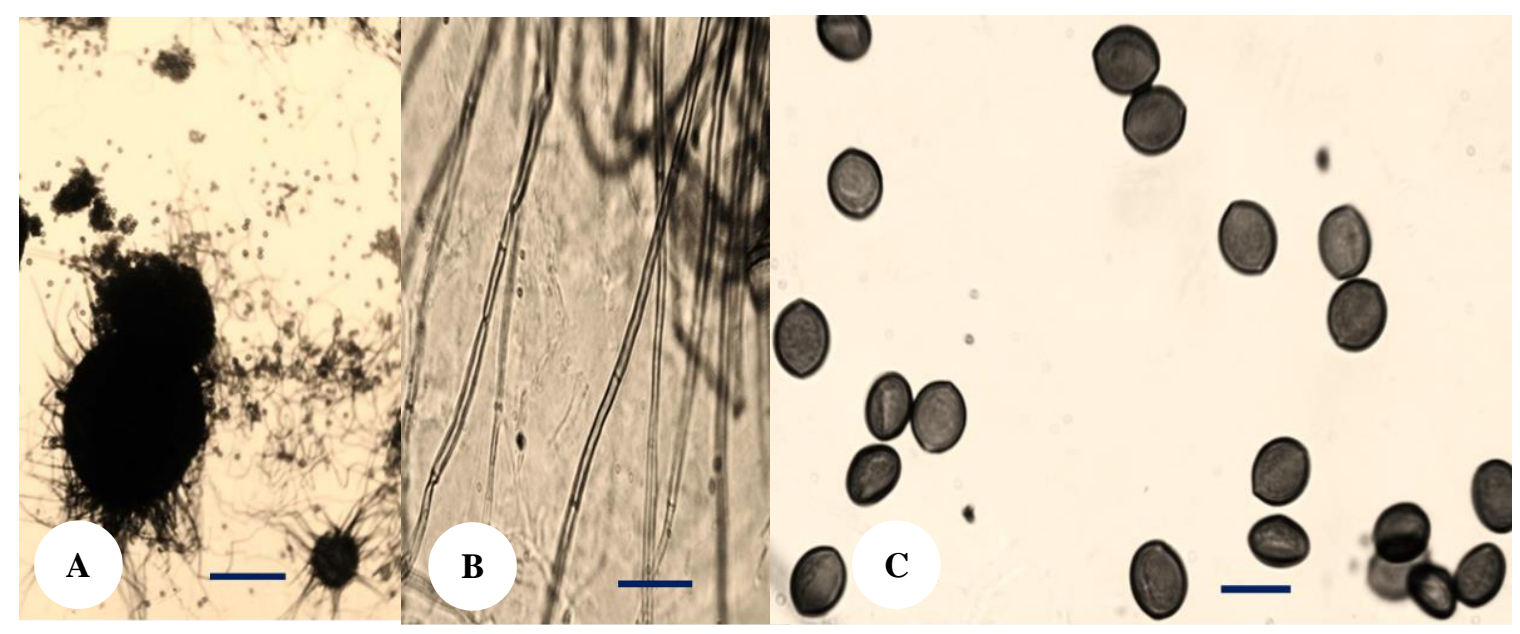

Figure 4. Chaetomium ascotrichoides. A. Ascoma. B. Ascomatal hairs. C. Ascospores. Bars: A = $100 \mu \mathrm{m} ; \mathrm{B}=30 \mu \mathrm{m} ; \mathrm{C}=11 \mu \mathrm{m}$.

\section{Chaetomium subaffine}

Chaetomium subaffine Sergeeva, Not. Syst. sect. Crypt. Inst. Bot. Acad. Sci. 14: 148. 1961. (Figure 5)

This species was characterized by superficial, dark, obovate, or ovate ascomata with dimensions of $220-410 \mu \mathrm{m}$ $\times 180-340 \mu \mathrm{m}$, olivaceous or dark in reflected light. The ascomatal wall exhibited textura intricata in surface view and was brown. The hairs were erect to flexuous, septate, verrucose, generally unbranched and tapering towards the tips, and 2.6-4.2 $\mu \mathrm{m}$ in diameter near the base. This species had eight ascospores within clavate and sometimes slightly fusiform evanescent, 17-36 $\mu \mathrm{m}$-long asci. The ascospores were bilaterally flattened limoniform, and usually biapiculate, when mature become brown, 11.5-13.5 (-14) $\mu \mathrm{m} \times 8-10 \mu \mathrm{m} \times 6-8.2 \mu \mathrm{m}$ in size, and possessed an apical germ pore. Anamorph not observed.

Colony morphology: Colonies exhibited good growth and matured within 7-10 days on OA medium at $25{ }^{\circ} \mathrm{C}$. They were nearly $45-50 \mathrm{~mm}$ in diameter, black, and had abundant white aerial hyphae. They were uncolored in reverse light.

Material examined: this fungus was isolated from two soil samples taken from Alkarmah and Aljazera, Basrah Province. GeneBank accession number LC600693.

Given its large ascospores $(11-15 \mu \mathrm{m} \times 8-11 \mu \mathrm{m} \times 7$ $8.5 \mu \mathrm{m}$ ), von Arx et al. (1986) maintained that $C$. subaffine is a separate species and distinguished it from $C$. globosum, which has smaller ascospores $(9-12 \mu \mathrm{m} \times 8-10 \mu \mathrm{m} \times 6-8$ $\mu \mathrm{m})$. Recent molecular studies revealed that this fungus is closely related to Chaetomium spiculipilium, Chaetomium cochliodes, and Chaetomium pseudocochliodes. However, we can distinguish it from the other species by its large ascospores and ascomata, which are covered by abundant white aerial mycelia (Wang et al. 2016 b).

\section{Collariella bostrychodes}

Collariella bostrychodes (Zopf) X. Wei Wang \& Samson, comb. nov. Stud. Mycol. 84: 158 (2016 a). (Figure 6)
Basionym: Chaetomium bostrychodes Zopf, Abh. Bot. Ver. Prov. Brandenburg 19:173. 1877.

This species was characterized by superficial, pale greenish-gray, subglobose, or ovate ascomata that were $210-250 \mu \mathrm{m} \times 160-240 \mu \mathrm{m}$ in size, gray in reverse light, and had a black collar around the ostiole. The ascomatal wall exhibited textura angularis and was brown. Around the ostiole the hairs were spirally coiled; obviously rough, septate, dark brown in the upper part, 3.5-6.5 $\mu \mathrm{m}$ in diameter near the base. This species had eight ascospores within clavate or fusiform, evanescent, 20-32 $\mu \mathrm{m}$-long asci. The ascospores were limoniform, bilaterally flattened, turn pale brown when mature, 6-7.5 $\mu \mathrm{m} \times 4.5-7 \mu \mathrm{m} \times 4-5 \mu \mathrm{m}$ in size, and possessed apical germ pores. Anamorph stage unknown.

Colony morphology: Colonies exhibited good growth and matured within 7 days on OA medium at $25{ }^{\circ} \mathrm{C}$. They were nearly $30-40 \mathrm{~mm}$ in diameter and were black in color and uncolored in reverse.

Material examined: this fungus was isolated from three soil samples collected from Abu-Alkasib, Almdinah, and Aljazera, Basrah Province. GeneBank accession number LC600692.

This genus derives its name from the dark collar that covers the ascomatal ostiole pore. On the basis of morphological and molecular evidence, scientists have classified this genus into two closely related subclades (Wang et al. 2019). The species belonging to this genus possess ascomata with high morphological diversity. The characteristics of our specimen corresponded to that of Wang et al.(2016 a \& 2019). Strong evidence shows that this fungus produces a toxic secondary metabolite called chaetochromin ( Dosen et al. 2017).

\section{Ovatospora brasiliensis}

Ovatospora brasiliensis (Batista \& Pontual) Wang \& Samson, comb. nov., Stud. Mycol. 84: 207 (2016a). (Figure 7)

Basionym: Chaetomium brasiliense Batista \& Pontual, Bol. Agr. Com. Pernambuco 15: 70. 1948. 


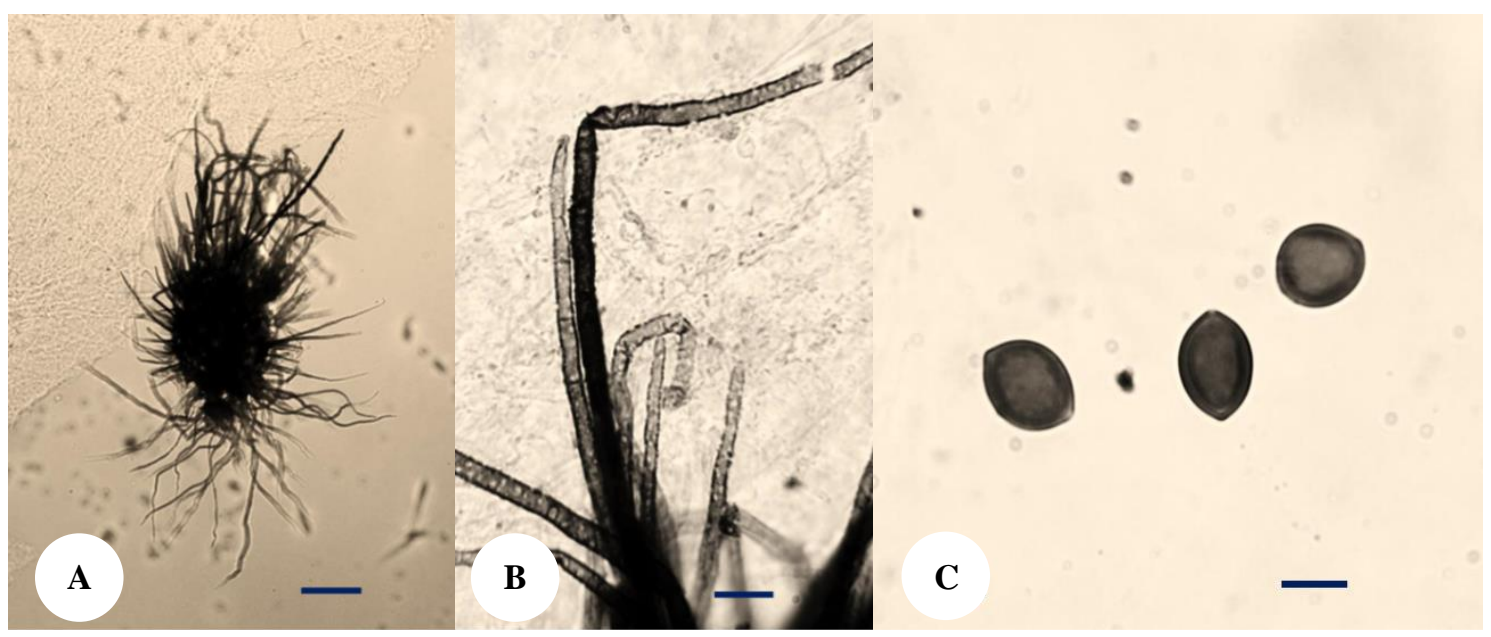

Figure 5. Chaetomium subaffine. A. Ascoma. B. Ascomatal hairs. C. Ascospores. Bars: A = $100 \mu \mathrm{m} ; \mathrm{B}=14 \mu \mathrm{m} ; \mathrm{C}=8 \mu \mathrm{m}$.

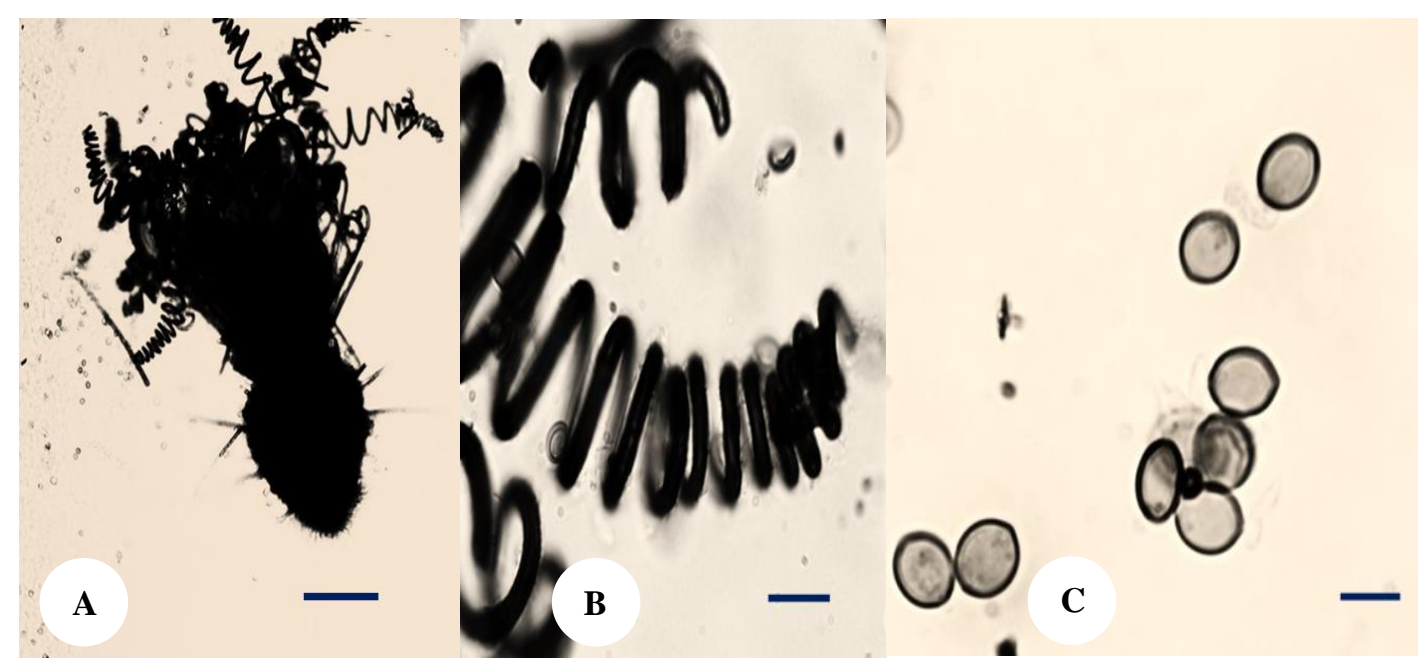

Figure 6. Collariella bostrychodes. A. Ascoma. B. Ascomatal hairs. C. Ascospores Bars: A = $100 \mu \mathrm{m} ; \mathrm{B}=20 \mu \mathrm{m} ; \mathrm{C}=6 \mu \mathrm{m}$.
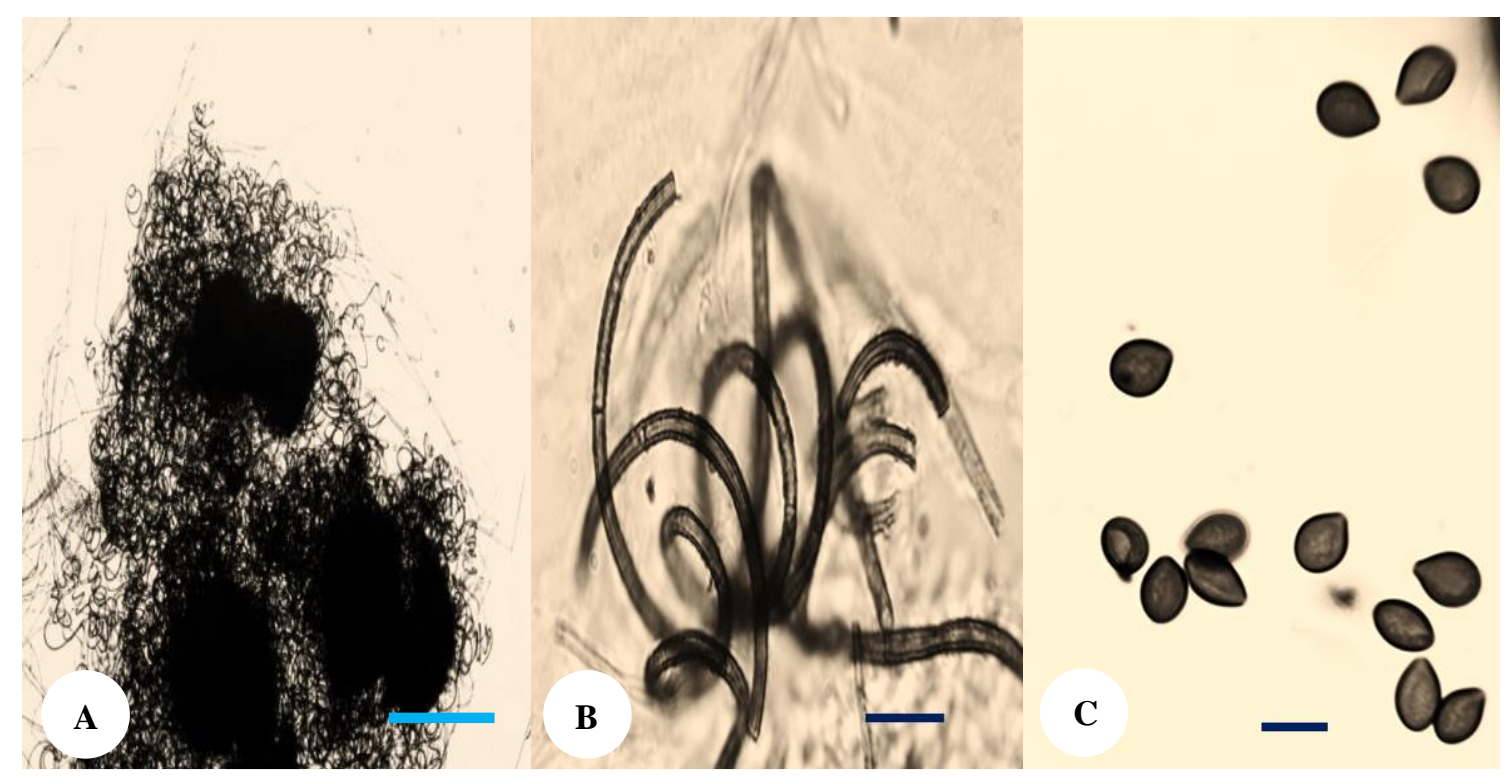

Figure 7. Ovatospora brasiliensis. A. Ascoma. B. Ascomatal hairs. C. Ascospores. Scale bars: A=100 $\mu \mathrm{m} ; \mathrm{B}=10 \mu \mathrm{m} ; \mathrm{C}=9 \mu \mathrm{m}$. 
This species was characterized by superficial, pale gray, subglobose, or globose ascomata $85-135 \mu \mathrm{m} \times 72-115 \mu \mathrm{m}$ in size, pale olivaceous gray in reverse light. The ascomatal wall presented textura angularis in surface view and was brown. The hairs were loosely coiled or undulate in the upper part and erect in the lower part and obviously rough, septate, grayish to brown in color, and 2-3.7 $\mu \mathrm{m}$ in diameter in the upper part. This species had eight ascospores within cylindrical, evanescent, 34-42 $\mu \mathrm{m}$-long asci. The ascospores were ovate, bilaterally flattened, turned brown when mature, 6.5-7.7 $\mu \mathrm{m} \times 5.3-6.2 \mu \mathrm{m} \times 5$ $6.7 \mu \mathrm{m}$ in size, and had apical germ pores at the attenuated end. Anamorph stage unknown.

Colony morphology: Colonies exhibited good growth and matured within 7 days on OA medium at $25^{\circ} \mathrm{C}$. They were nearly $40-50 \mathrm{~mm}$ in diameter, pale gray to pale olivaceous gray, and black in reverse.

Material examined: the examined materials were isolated from three agricultural soil samples collected from Abu-Alkasib, Basrah Province. GeneBank accession number LC600696.

The name of this genus came from the ovate to broadly ovate ascospores of all of its species (Wang et al. 2016 a). This species was previously isolated from moist jute cloth and from dried freshwater fish, prawns, and shrimps (Wang et al. 2016; Ara et al. 2020). To our knowledge, this is the first record of this species from agricultural soil. This fungus forms a sister lineage to $O$. mollicella. The phylogenetic tree clustered these two species together. This result was similar to that reported by Wang et al.(2016 a) \& Ara et al.(2020). We can distinguish $O$. mollicella on the basis of its large ascospores, which have dimensions of 8$9.5 \mu \mathrm{m} \times 7-8 \mu \mathrm{m} \times 6-7 \mu \mathrm{m}$ (Wang et al. 2016 a). $O$. brasiliensis is of medical interest considering that it was isolated from a patient with spinocellular carcinoma, which is a case of otitis externa (Hubka et al. 2011).

In conclusion, this study was the first study for the family Chaetomiaceae in Iraq that relied on molecular analysis. The species within this family having diverse morphological characteristics, so the identification of these fungi depending on morphological characters is not enough and must be supported by modern phylogenetic techniques. This study identified five species with three genera Amesia, Collariella, and Ovatospora all of which are recorded for the first time in Iraq.

\section{ACKNOWLEDGEMENTS}

The authors are grateful to Dr. Maithm Al-Shaheen for his help in photographing the fungal samples.

\section{REFERENCES}

Abdel-Azeem AM. 2020. Recent developments on genus Chaetomium Springer Nature, Switzerland

Adhikari M, Gurung SK, Kim HS, Bazie S, Lee G, Lee HB, Lee YS 2017. Three new records of ascomycetes isolates from field soils in Korea. Microbiol 45: 327-337. DOI: 10.5941/MYCO.2017.45.4.327.
Aggarwal A, Sharma V, Kharbikar LL, Renu.2008. Molecular characterization of Chaetomium species using URP-PCR. Genet Mol Biol 31: 943-946. DOI: 10.1590/S1415-47572008005000011.

Altschul SF, Madden TL, Schäffer AA, Zhang J, Zhang Z, Miller W Lipman DJ.1997. Gapped BLAST and PSI-BLAST: a new generation of protein database search programs. Nucleic Acids Res 25(17): 33893402. DOI: $10.1093 /$ nar/25.17.3389.

Ara I, Sultana R, Chanda IF, Alam N. 2020. First report on Ovatospora brasiliensis from freshwater dried shrimp and prawn in Bangladesh. Int J Fauna Biol Stud 7: 43-47.

Davet P, Rouxel F. 2000. Detection and isolation of soil fungi. Science Publishers, Enfield, NH.

de Hoog GS, Ahmed SA, Najafzadeh MJ, Sutton DA, Keisari MS, Fahal AH, Eberhardt U, Verkleij GX, Xin L, Stielow B, van de Sande WJ. 2013. Phylogenetic findings suggest possible new habitat and routes of infection of human eumycetoma. PLoS ONE 7: 2229. DOI: 10.1371/journal.pntd.0002229.

Dosen L, Nielsen KF, Clausen G, Andersen B. 2017. Potentially harmful secondary metabolites produced by indoor Chaetomium species on artificially and naturally contaminated building materials. Indoor Air 27: 34-46. DOI: 10.1111/ina.12290.

Eric WS, Mark C, Karen C, Kim DP, Conrad LS, Stephen TSh, Ilene K.2020. Gen bank. Nucleic Acids Res 8: 49(D1): D92-D96. DOI: 10.1093/nar/gkaa1023.

Friggens NL, Taylor JE, Koukol O. 2017. Diversity and community composition of aquatic ascomycetes varies between freshwater, estuarine and marine habitats in western Scotland. Mycosphere 8: 1267-1287. DOI: 10.5943/MYCOSPHERE/8/9/2.

Guarro J, Gene J, Stachigel AM, Figueras J. 2012. Atlas of soil ascomycetes. CBS-KNAW Fungal Biodiversity Center Utrecht. Netherland.

Hubka V, Mencl K, Skorepova M, Lyskova P, Zalabska E. 2011. Phaeohyphomycosis and onychomycosis due to Chaetomium spp., including the first report of Chaetomium brasiliense infection.Med Mycol 49: 724-733. DOI: 10.3109/ 13693786. 2011.572299.

Katoh R, Rozewicki J, Yamada KD. 2019. MAFFT online service: multiple sequence alignment, interactive sequence choice and visualization. Briefings in bioinformatics 20: 1160-1166. DOI: 10.1093/bib/bbx108.

Li J, Zhao MN, Wang ZW. 2012. Growth temperature of Chaetomium species and its taxonomic value. Mycosystema 31: 2013-222.

Mirhendi H, Makiumura K, Khoramizadeh M, Yamagushi H. 2006. A one-enzyme PCR-RFLP assay for identification of six medically important Candida species. Japa J Medi Mycol 47: 225-229. DOI: $10.3314 / \mathrm{jjmm} .47 .225$

Quyet NT, Thanh ND, Cuong HV, Huong BTL, Soytong K. 2018. Molecular Identification of Chaetomium species from Soil in Vietnam. Intl J Agric Technol 14 (2018): 225-232.

Ruppavalli MV, Muthamilan M, Nakkeeran S, Subramanian KS. 2019. Phenotypic and molecular characterization of Chaetomium globosum (Gustav Kunze) from different microhabitats of Tamil Nadu, India. Int J Curr Microbiol App Sci 8: 1496-1506. DOI: 10.20546/ijcmas.2019.806.180.

Samson RA, Houbraken J, Thrane U, Frisvad JC, Andersen B. 2010. Food and indoor fungi. CBS Laboratory Manual series no. 2. CBS-KNAW Fungal Biodiversity Centre, Utrecht, The Netherlands

Sekhar VC, Prameeladevi T, Kamil D, Ram D. 2018. Studies on Phylogeny of Chaetomium species of India. Int J Curr Microbiol App Sci 7: 3154-3166. doi:10.20546/ijcmas.2018.708.337.

von Arex JA, Guarro J, MJ, Figueras MJ. 1986. The ascomycetes genus Chaetomium, Beigefte zur Nova Hedwegia 84:1-162. DOI: 10.1016/0265-3036(89)90019-5

Wang X, Wang XL, Liu F, Zhao X, Li J, Cai L. 2014. Phylogenetic assessment of Chaetomium indicum and allied species, with the introduction of three new species and epitypification of C. funicola and C. indicum. Mycol Progress 13:719-732. DOI:10.1007/s11557013-0955-x.

Wang XW, Houbraken J, Groenewald JZ, Meijer M, Andersen B, Nielsen KF, Crous PW, Samson RA. 2016a. Diversity and taxonomy of Chaetomium and Chaetomium-like fungi from indoor environments. Stud Mycol 84: 145-224. DOI: 10.1016/j.simyco.2016.11.005.

Wang XW, Lombard L, Groenewald ZJ, Li J, Vidiera SIR, Samson AR, Liu ZX, Crous WP. 2016b. Phylogenetic reassessment of the 
Chaetomium globosum species complex. Persoonia 36: 83 - 133. DOI: $10.3767 / 003158516$ X689657.

Wang XW, Yang FY, Meijer M, Kraak B, Sun BD, Jiang YL, Wu YM, Bai FY, Seifert KA. 2019. Redefining Humicola sensu stricto and related genera in the Chaetomiaceae. Stud Mycol 93: 65-153. DOI: 10.1016/ j.simyco. 2018.07.001

Zhang Y, Wu W, Cai L. 2017. Polyphasic characterisation of Chaetomium species from soil and compost revealed high number of undescribed species. Fung Biol 121: 21-43. DOI: 10.1016/j.funbio.2016.08.012. 